African Crop Science Journal by African Crop Science Society is licensed under a Creative Commons Attribution 3.0 Uganda License. Based on a work at www.ajol.info/ and www.bioline.org.br/cs DOI: http://dx.doi.org/10.4314/acsj.v24i4.2

\title{
CARACTÉRISATION DES ITINÉRAIRES TECHNIQUES DE LA CULTURE DE COURGETTE AU PÉRIMÈTRE PUBLIC IRRIGUÉ DE CHOTT MERIEM-TUNISIE
}

\author{
A. LAHDHIRI and M. MEKKI \\ 1. Département des sciences biologiques et protection des végétaux \\ UR.04AGRO4 : Invertébrés, Microorganismes, malherbes nuisibles : Méthodes alternatives de lutte, Institut \\ Supérieur Agronomique de Chott Meriem, Université de Sousse, Tunisie \\ Auteur correspondant : anissalahdhiri@yahoo.fr
}

(Received 14 July, 2016; accepted 12 September, 2016)

\section{RÉSUMÉ}

Les périmètres publics irrigués (PPI), en Tunisie, ont été créés pour développer les conditions socio-économiques des agriculteurs et faire face à l'irrégularité des précipitations. Aujourd'hui, l'activité de certains périmètres est en deçà de leurs potentialités. Le diagnostic des itinéraires techniques des cultures est un pré-requis de tout programme de développement de ce secteur stratégique. L'objectif de cette étude est le diagnostic de l'itinéraire technique de la courgette (Cucurbita pepo L.) au PPI de Chott Meriem. Ce diagnostic est basé sur un suivi de cinq agriculteurs, à travers l'enregistrement de sept descripteurs que sont: précédent cultural, plantation, irrigation, fertilisation, désherbage, traitements phytosanitaires, et rendement. Les rendements enregistrés sont faibles $\left(<33 \mathrm{~T} \mathrm{ha}^{-1}\right)$. L'implantation à contre temps de la culture, son irrigation et sa protection phytosanitaire aléatoires, et une rotation parfois inadaptée sont corrélés avec cette faible productivité. Souvent, les apports, d'engrais étaient en dessous des doses recommandées : 11-68\% de N, 2-126\% de $\mathrm{P}_{2} \mathrm{O}_{5}$ et $<11 \%$ de $\mathrm{K}_{2} \mathrm{O}$. Ces résultats indiquent l'absence d'itinéraire technique planifié de cette culture et reflètent l'absence de système de culture.

Mots Clés : Cultures maraîchères, Itinéraire technique, Techniques culturales

\begin{abstract}
The public irrigated area (PIA), in Tunisia, has been created to develop the socio-economic conditions of farmers and cope with rainfall irregularity. Today, the activity of some areas is below their potential. Diagnosis of the crop management approaches is required for every development program of this strategic sector. The objective of this study is the diagnosis of the approaches used in managing zucchini (Cucurbita pepo L.) cultivation in the PIA of Chott Meriem. This diagnosis is based on the follow-up of five farmers, through the registration of seven descriptors: previous crop, planting, irrigation, fertilization, weed control, plant protection treatments, and yield. The study revealed low yields $\left(<33 \mathrm{t} \mathrm{ha}^{-1}\right)$. The inappropriate implantation date, the hazardous irrigation and plant protection, and sometimes the unsuitable rotation are correlated with the low productivity. Often, the fertilizers inputs were below recommended rates: $11-68 \% \mathrm{~N}, \mathrm{P}_{2} \mathrm{O}_{5}$ and $2-126 \%<11 \% \mathrm{~K}_{2} \mathrm{O}$. These results are indication that there is lack of planned crop management of zucchini and crop system concept.
\end{abstract}

Key Words: Vegetable crops, Crop management, cropping practices 


\section{INTRODUCTION}

En Tunisie, les cultures irriguées occupent $7 \%$ de la surface agricole utile et représentent $95 \%$ de la production maraîchère (Laajimi, 2007). Les périmètres irrigués ont été créés pour permettre aux agriculteurs de faire face à l'irrégularité des précipitations et améliorer leurs conditions de vie. L'activité de certains périmètres reste en deçà de leurs potentialités. Ils souffrent de la sous exploitation, la non maîtrise des techniques de production et l'endettement des agriculteurs (TAP, 2015). Dans notre étude, nous nous intéressons au périmètre public irrigué (PPI) de Chott Meriem (Sousse, Centre-Est de la Tunisie).

Ce périmètre est menacé par la pression de l'étalement urbain et la rareté de la main d'œuvre à cause des changements socio-économiques du pays (Houimli, 2008). Ces mutations menacent sa durabilité. D'où, le besoin d'innovation des systèmes de cultures. Cette innovation doit prendre en compte les pratiques culturales des agriculteurs. L'analyse de ces pratiques et des logiques qui les déterminent, s'appuie sur deux concepts agronomiques : l'itinéraire technique (ITK) défini par "la suite logique et ordonnée de techniques culturales appliquées à une espèce cultivée" (Sébillotte, 1978) et le système de culture qui est "l'ensemble des modalités techniques mises en ouvre sur des parcelles traitées de manière identique" (Sébillotte, 1990) et qui s'applique à une succession de cultures.

Le diagnostic agronomique est un outil performant qui permet d'identifier les pratiques et les systèmes de culture adoptés (Guillou et al., 2013) ; déterminer les facteurs limitant les performances de ces pratiques; et mettre en évidence les leviers d'action en mesure d'améliorer les performances de l'exploitation (Loyce et Wery, 2006). Il fournit les informations nécessaires à l'évaluation des avantages et limites des systèmes pratiqués dans leur globalité (Hillger et al., 2006). Et, il aide à cerner les priorités de recherche contribuant à la durabilité des systèmes de production (Byerlee, 1991). Dans ce travail, notre objectif est de faire le diagnostic des ITK de la culture de courgette (Cucurbita pepo L.) au PPI de Chott Meriem.
Site d'étude. Le PPI de Chott Meriem se situe dans la région du Sahel tunisien (Latitude: 35,919897, Longitude: 10,565203), caractérisée par un climat méditerranéen tempéré (Fig. 1). En hiver, la température moyenne est voisine de $12^{\circ} \mathrm{C}$; les moyennes maximales diurnes évoluent autour de $17^{\circ} \mathrm{C}$, alors que les moyennes minimales nocturnes sont de $8^{\circ} \mathrm{C}$. L'été se caractérise par de fortes chaleurs (température moyenne de $29^{\circ} \mathrm{C}$ ). Le réchauffement journalier de l'air devient perceptible dès le mois de mai et atteint son maximum en août. Des vents sahariens du Sudouest, chauds et secs, rehaussent la température à des niveaux dépassant $40^{\circ} \mathrm{C}$ (Mohamed, 2009).

Suivi des ITK de la culture de courgette. Notre approche de travail vise le suivi des ITK de la culture de courgette chez un groupe d'agriculteurs de Chott Meriem. (Houimli, 2008) a affirmé que les agriculteurs du PPI dévoilent des caractéristiques communes : la majorité des exploitations sont de petite taille (moins d'un hectare), même règles d' accès à l'eau d'irrigation, centrage sur les cultures maraîchères de rente; préférence de l'autofinancement aux crédits agricoles, etc. De ce fait, les agriculteurs du PPI sont considérés homogènes. Et par suite, les agriculteurs concernés par notre étude, comme sous ensemble du PPI, sont considérés un échantillon homogène et représentatif. Le besoin de mesure et quantification des résultats d'une part et la rareté des moyens mis à disposition nous ont mené à concentrer nos efforts sur un échantillon représentatif.

On a proposé à plusieurs agriculteurs d'adhérer à cette étude. Seulement dix agriculteurs ont exprimé leur approbation préliminaire de collaboration. Plusieurs réunions, à l'Institut Supérieur Agronomiques (ISA) de Chott Meriem comme aux champs, étaient nécessaires afin d'expliquer aux agriculteurs la méthodologie de suivi qui leur était, à la fois, nouvelle et étrange. Puis, cinq agriculteurs ont décidé de continuer l'expérience vu leur intérêt à évaluer leurs ITK pour des fins d'amélioration et de modernisation. 
Une fiche de suivi des ITK de la courgette est élaborée en s'inspirant du registre phytosanitaire et du cahier de fertilisation et des amendements élaborés par certaines chambres d'agricultures françaises. Sept descripteurs ont été enregistrés : précédent cultural, plantation, irrigation, fertilisation, désherbage, traitements phytosanitaires, et rendement (Tableau 1). Cette fiche a pour objectif de recueillir le maximum de données relatives aux ITK de la culture en absence d'un système d'enregistrement des pratiques culturales au sein de ces exploitations. Cette fiche a été communiquée aux agriculteurs pour les inciter à enregistrer toutes ces pratiques relatives à la culture.

Les agriculteurs qui ont positivé et adhéré à notre étude, se sont impliqués sérieusement. Les visites régulières nous ont permis de s'assurer du bon enregistrement des données et leur vérification. Les entretiens directs avec les

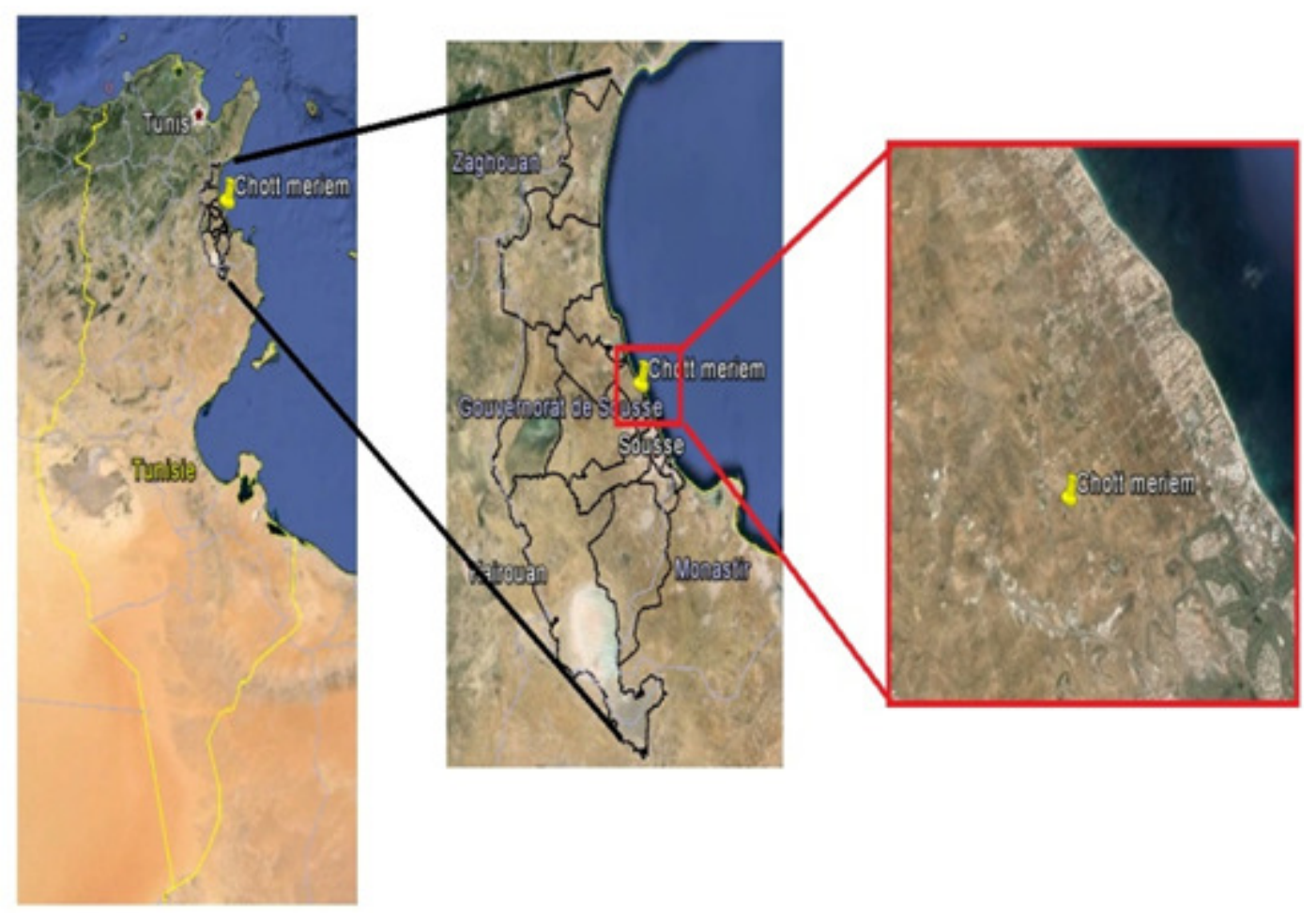

Figure 1. Localisation géographique du PPI de Chott Meriem, Sousse, Tunisie (Google Earth, 2015)

TABLEAU 1. Enregistrements des itinéraires techniques de la culture de courgette auprès de cinq agriculteurs du PPI de Chott Meriem

\begin{tabular}{ll}
\hline Pratique culturale & Enregistrements \\
\hline Précédent cultural & Culture, date d'installation, date de récolte \\
Plantation/semis & Date, variété, densité, durée du chantier \\
Irrigation & Système d'irrigation, dates, volumes apportés \\
Fertilisation & Engrais, quantités appliquées, dates d'application \\
Entretien du sol & Dates, outils, durées des chantiers \\
Traitements phytosanitaires & Produits, dates d'application, doses, quantités de bouillie, durées des chantiers \\
Récolte & Dates, durée du chantier, rendement \\
\hline
\end{tabular}


agriculteurs ont permis d'éclaircir les détails nécessaires. Les visites se sont déroulées tous les 10-15 jours au cours de la période s'étalant de novembre 2014 à juin 2015 (soit en moyenne 21 visites par agriculteur).

\section{RÉSULTATS ET DISCUSSION}

Caractérisation des exploitations agricoles. $\mathrm{La}$ culture de courgette chez le groupe d'agriculteurs de notre étude est pratiquée sur des petites superficies ne dépassant pas 0.6 ha pour chaque agriculteur. D'ailleurs, ces exploitations maraîchères sont de petite taille (Tableau 2). Les agriculteurs ne sont pas les propriétaires des terres ils sont des exploitants à titre locatif. L'activité agricole est la source principale de revenu de quatre agriculteurs; le cinquième est fonctionnaire. L'occupation du sol est dominée par la culture de pomme de terre : en effet les conditions climatiques du PPI de Chott Meriem permettent trois saisons de culture de la pomme de terre (arrière saison, primeur et saison). En plus, elle représente une tradition des agriculteurs du PPI (Houimli, 2008). D'ailleurs, plus de $70 \%$ de la superficie exploitée par des agriculteurs étudiés est consacrée à la pomme terre. Les autres cultures de plein champ sont la courgette, la tomate, le piment, le haricot, la laitue, la fève, le concombre, la betterave, et le brocolli. Les cultures sous serres sont essentiellement la tomate, le piment et les cucurbitacées. L'élevage est quasi absent. L'activité agricole dans ces exploitations est assurée par une main d'œuvre occasionnelle, marquée par une forte dominance des femmes dépassant les $75 \%$ vue leur coût moins cher. La surface limitée des parcelles (de 0.25 à 0.6 ha) fait que la mécanisation est très peu développée. D'ailleurs, seulement deux agriculteurs possèdent leurs propres tracteurs.

Caractérisation des ITK de la courgette. Le précédent cultural de la courgette est une solanacée (pomme de terre, piment ou tomate) chez trois agriculteurs (Tableau 3 ). Cette pratique influe négativement sur le rendement. D'ailleurs, (Espagnacq, 2015) avertit que les solanacées ne sont pas des précédents favorables des cucurbitacées. Deux agriculteurs ont précédé la courgette d'une autre culture de courgette.

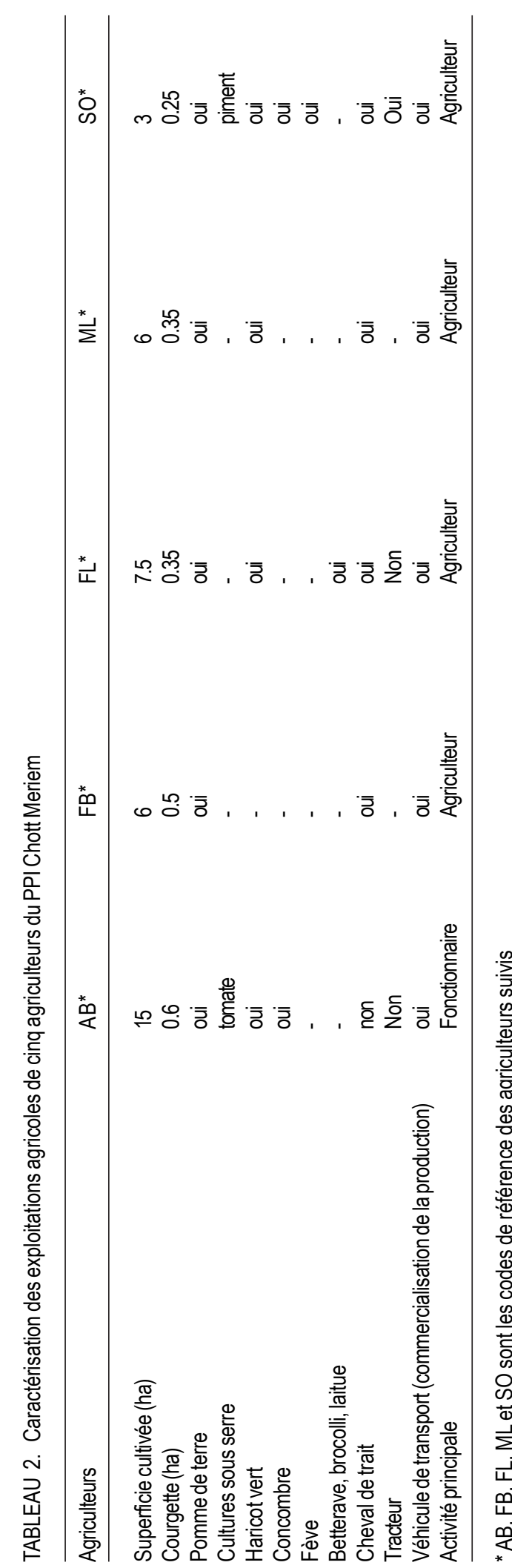


Cependant, une telle monoculture pourrait entrainer des problèmes affectant les potentialités de la culture (expansion des maladies et des ravageurs, perte de la fertilité des sols, invasion des mauvaises herbes ...). C'est la raison pour laquelle Abatzian et al. (2003) conseillent de respecter au moins trois ans entre deux cultures de courgette successives. Le gombo (Abelmoschus esculentus L. (Moench)) est un précédent cultivé par le cinquième agriculteur de notre groupe. Bien qu'il coupe avec la monoculture et les précédents défavorables, son expansion sous les conditions climatiques du PPI n'est pas faisable du fait qu'elle est très exigeante en chaleur, lumière et irrigation (Skiredj et al., 2012) ; alors que la disponibilité de l'eau d'irrigation en saison chaude est limitée dans le PPI Son adoption s'explique par la volonté de l'agriculteur de diversifier la production dans son exploitation. D'ailleurs, c'est le seul qui tente à diversifier les cultures dans son exploitation. Les quatre restants sont orientés plutôt vers la simplification et le profit économique qui les ont conduits à répéter les mêmes cultures voire même à la monoculture sans avoir recours à une stratégie planifiée. Aujourd'hui, ces schémas ont atteint leurs limites, partout dans le monde, en termes économiques (plafonnement des rendements) et environnementaux.

Les résultats obtenus nous laissent deviner, dès maintenant déjà, que l'élaboration du rendement attendu sera altérée à cause d'une telle succession culturale hasardeuse. Nous encourageons les agriculteurs (ceux du groupe étudié, et par projection, ceux du PPI) à trouver l'équilibre entre diversité des cultures et efficacité de la production. Les services régionaux de vulgarisation agricole doivent les soutenir dans cette démarche Ils peuvent les sensibiliser, d'abord, sur les avantages acquis en choisissant un précédent adéquat tels que l'amélioration de la structure et la fertilité du sol, le bris du cycle des ravageurs et des maladies, la réduction de l'application des engrais... Et puis, le choix des cultures doit répondre aux particularités du PPI de Chott Meriem. En effet, Abatzian et al. (2003) affirment que la courgette sera mieux placée en tête de rotation ou après un engrais vert (féverole, sorgho, colza), ou après l'ail, l'oignon, les choux, la laitue et les céréales (Conseil et al., 2009). Cependant, les cultures adéquates ailleurs ne sont pas forcément les meilleures dans ce PPI, d'où le besoin de validation dans les conditions locales (conditions climatiques, commercialisation, technicité. Par exemple, la fèverole, identifiée dans la littérature comme un bon précédant de la courgette, est difficile à introduire puisqu'elle n'est pas une culture de rente et son bénéfice financière est limité..

La durée d'interculture est jugée longue (1217 semaines) chez trois agriculteurs; elle est seulement d'une à deux semaines pour les deux autres. Sa durée est en relation directe avec le degré d'occupation de l'agriculteur, la disponibilité de la main d'œuvre, le degré d'occupation du sol, les saisons de culture, etc. La longue interculture s'explique par les cultures tardives d'été qui ont entravé le démarrage à

TABLEAU 3. Précédents culturaux et implantation de la culture de courgette de saison chez cinq agriculteurs du PPI de Chott Meriem

\begin{tabular}{llllll}
\hline Agriculteur & $\mathrm{AB}$ & $\mathrm{FB}$ & $\mathrm{FL}$ & $\mathrm{ML}$ & $\mathrm{SO}$ \\
\hline Précédent cultural & Piment + tomate & Piment & Gombo & Courgette & Pomme de terre \\
Interculture (semaines) & 12 & 14 & 17 & 1 & 2 \\
Cultivars & Super jadida & ARTE & Super jadida & Super jadida & Super jadida \\
Semis/Plantation $(\mathrm{S} / \mathrm{P})$ & $\mathrm{P}$ & $\mathrm{P}$ & $\mathrm{S}$ & $\mathrm{S}$ & $\mathrm{S}$ \\
${\text { Dates }(\mathrm{S} / \mathrm{P})^{1}}_{\text {Densités } \mathrm{S} / \mathrm{P})^{2}}^{15 / 11 / 2014}$ & $10 / 1 / 2015$ & $10 / 12 / 2014$ & $1 / 1 / 2015$ & $1 / 1 / 2015$ \\
Ecartements $^{3}$ & 12500 & 16000 & 16600 & 25600 & 25600 \\
\hline
\end{tabular}

\footnotetext{
1. Date de semis/plantation

2. Densité de semis/plantation (plants ha ${ }^{-1}$ )

3. Ecartements (cm)
} 
temps de la nouvelle saison agricole causant son abandon. Elle est déconseillée puisqu'elle affecte l'utilisation efficiente des parcelles en passant au moins le quart de l'année sous forme de terre nue. Ceci est la conséquence de l'absence de calendrier cultural défini au préalable et l'instabilité de l'approvisionnement en eau d'irrigation. Dans le cas de l'interculture courte, les deux agriculteurs ont plus de chance d'améliorer leur bénéfice suite à un meilleur taux d'utilisation des terres. A la lumière des résultats de l'échantillon des agriculteurs étudiés, on leur recommande (comme aussi aux reste agriculteurs $\mathrm{du}$ PPI) de veiller à raccourcir l'interculture et d'approfondir leur réflexion sur l'assolement et la rotation des cultures. Et, même si on n'arrive pas à installer une culture principale, on évite de laisser la terre nue à travers l'installation d'une culture dérobée ou un couvert végétal. D'après (Montagnon, 2004), cette pratique améliore la qualité du sol, limite la multiplication des adventices et contribue à la maitrise de certains ravageurs.

Le cultivar le plus fréquemment utilisé était "Super jadida". Ceci a été observé chez quatre agriculteurs. Le cinquième a cultivé "ARTE" (Tableau 3). Alors que plusieurs cultivars sont enregistrés en Tunisie (Marzouka, Top Kapia, Revera, Mayadha, Safi, etc.). Le choix des agriculteurs est limité par les cultivars disponibles dans les points de vente de Chott Meriem. D'ailleurs, l'agriculteur qui s'écarte du groupe par son choix s'est approvisionné dans un point de vente en dehors de Chott Meriem. Il a justifié son choix par la résistance d'ARTE au virus "Zucchini Yellow Mosaic Virus" (ZYMV) et son potentiel de rendement. Elle est recommandée en culture de saison alors que "Super jadida" est recommandé en culture de primeur (JORT, 2002). Il importe de choisir le cultivar en fonction de la période de semis de la culture pour profiter d'une végétation dense en vue de réprimer les adventices (Schonbeck, 2015)

Le semis en plein champ est pratiqué chez trois agriculteurs mais deux ont opté pour la transplantation de jeunes plants élévés en pépinière. Cette transplantation est) recommandée puisqu'elle favorise une production hâtive de 36 à 38 jours et un rendement élevé (>50 \%) (Jellani et al., 2015). Le semis/ plantation s'est étalé sur trois mois (Tableau 3). Toutefois, et d'après les données climatiques de la saison 2014/2015, la meilleure période d'établissement de la courgette au PPI de Chott Meriem est située entre fin décembre et début janvier. Un semis hâtif exige une installation minutieuse des tunnels pour atteindre les exigences thermiques de végétation. Celles-ci sont de $20-22^{\circ} \mathrm{C}$ le jour et $17-18^{\circ} \mathrm{C}$ la nuit Garcia (2008). Ces températures n'ont pas été atteintes dans le PPI (Fig. 2). D'ailleurs, FAO (2015) recommande pour les régions semi-arides à hivers doux, comme la Tunisie, la culture de courgette sous couvert. Les cinq agriculteurs ont installé la courgette sous des tunnels couverts par un film thermique en polyéthylène pour l'aider à esquiver la période froide. Toutefois, ce film était fragilisé voire même déchiré par les utilisations antérieures. Cet état n'a pas permis le gain en température souhaité, la chose qui s'est répercutée négativement sur le démarrage de la culture et ultérieurement sur sa productivité.

Trois agriculteurs ont opté pour une densité

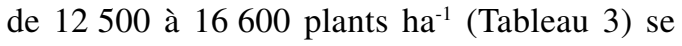
situant, ainsi, dans l'intervalle de densités recommandées dans les régions méditerranéennes en Algérie (11000 à 16000 plants ha ${ }^{-1}$ (ITCM, 2010)) et en France (12000 à 16000 plants ha $^{-1}$ (Garcia, 2008)). Toutefois, les deux autres agriculteurs ont pratiqué une densité nettement supérieure de 25600 plants ha $^{-1}$ ce qui pourrait représenter des charges supplémentaires en termes de semences nécessaires.

Tous les agriculteurs sont équipés d'un système d'irrigation goutte-à-goutte. Trois ont rapporté des quantités d'eau $>3000 \mathrm{~m}^{3} \cdot$ ha $^{-1}$ pour toute la saison culturale. Ces apports concordent avec les besoins de la culture suggérés qui sont de 3000-5000 $\mathrm{m}^{3} \mathrm{ha}^{-1}$ selon Garcia (2008). La fréquence d'irrigation a augmenté en passant d'une fois par semaine à jour après jour pendant les périodes de demande accrue. Le volume d'irrigation a augmenté, à son tour, progressivement en fonction des stades de développement de la culture avec un maximum au cours de la période de production des fruits (Tableau 4). D'ailleurs, les valeurs du coefficient cultural $(\mathrm{Kc})$ de la courgette soutiennent cette progression. Ce coefficient participe, à coté de l'évapotranspiration, dans l'estimation des 
besoins en eau d'une culture. Il dépend du climat et du stade de développement. D'après (Bouchy, 2011), Kc de la courgette varie de 0.4 à l'établissement de la culture à 1.2 au stade production. Les apports d'eau d'irrigation par les deux autres agriculteurs n'ont pas dépassé 1600 $\mathrm{m}^{3} \mathrm{ha}^{-1}$, largement en dessous des besoins de la courgette. Un de ces agriculteurs a abandonné sa culture; le deuxième a sous-estimé les besoins en eau de sa culture dès la phase d'établissement. Les répercussions sur le niveau de production seront considérables.

Les agriculteurs suivis ont apporté l'azote sous forme d'ammonitrate $(33.5 \%)$ ou de phosphate de diammonium. Le phosphore est apporté sous forme d'acide phosphorique ou de phosphate de diammonium. Et, la potasse est fournie sous forme de sulfate de potasse. Deux agriculteurs font appel, à une très faible quantité, d'un engrais composé (20.20.20). Par rapport aux doses recommandées, les apports de $\mathrm{N}, \mathrm{P}_{2} \mathrm{O}_{5}$ et $\mathrm{K}_{2} \mathrm{O}$ étaient, respectivement, de 11-68\%, 2 à $126 \%$, et $<11 \%$ pour toute la saison culturale (Tableau 5). Ces données illustrent une fertilisation aléatoire en l'absence d'une référence locale. Elle était insuffisante pour assurer un développement normal de la culture. La courgette s'est trouvée dépourvue de fertilisants à son démarrage; le premier apport d'engrais a eu lieu au stade floraison. Cependant, la courgette est exigeante

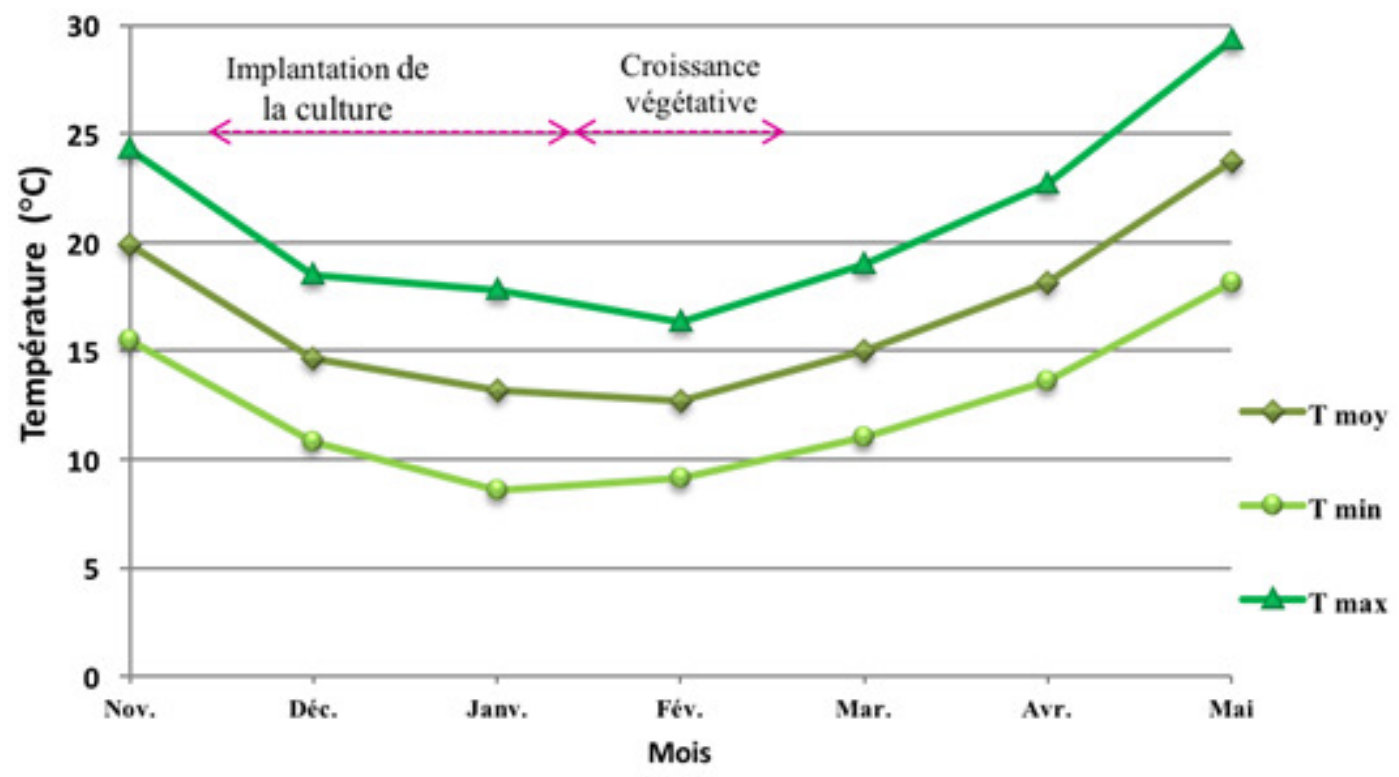

Figure 2. Température mensuelle moyenne au cours du cycle de culture de la courgette au PPI de Chott Meriem (INM, 2015)

TABLEAU 4. Apports d'eau $\left(\mathrm{m}^{3}\right.$ ha-1) en fonction du stade de la culture de courgette de saison chez cinq agriculteurs du PPI de Chott Meriem

\begin{tabular}{lrrrrrl}
\hline Stade de la courgette/Agriculteurs & $\mathrm{AB}$ & $\mathrm{FB}$ & $\mathrm{FL}$ & $\mathrm{ML}$ & $\mathrm{SO}$ & $\mathrm{Kc}^{1}$ \\
\hline Etablissement & 100 & 200 & 571 & 686 & 480 & 0,4 à 0,6 \\
Floraison & 333 & 100 & 343 & 686 & 480 & 0,8 \\
Production & 1167 & 2860 & 3600 & 3942 & 480 & 0,9 à 1,2 \\
Total $\left(\mathrm{m}^{3} / \mathrm{ha}\right)$ & 1600 & 3160 & 4500 & 5300 & 1450 & - \\
\hline
\end{tabular}

1. Coefficient cultural de la courgette (Bouchy, 2011) 
en fertilisants durant ses premiers stades de développement, vu son développement foliaire important et sa croissance très rapide (Abatzian et al., 2003). D'ailleurs, on a assisté, dans les parcelles suivies et à différents degrés, à un développement restreint et une couverture de sol peu étendue. Le rendement sera certainement pénalisé à cause de cette fertilisation déficiente. D'ailleurs, il a été rapporté que la cinétique de production de biomasse a un profil analogue à celle de consommation d'azote Ctifl (2000). Davantage, le déséquilibre du ratio $\mathrm{N} / \mathrm{K}$ réduit le rendement puisque ce rapport influe sur la formation des fleurs femelles (Abatzian et al., 2003).

Le nombre de traitements phytosanitaires de la courgette était de quatre à six sur toute la saison culturale, sauf pour l'agriculteur qui a abandonné sa culture (Tableau 6). Soixante dix pourcent de ces traitements sont anti-oïdium, appliqués de façon curative. L'oïdium est un ennemi redoutable des cucurbitacées (McGrath, 2007). Les agriculteurs ont utilisé des produits phytosanitaires non homologués sur la courgette dans au moins $50 \%$ des cas. Le surdosage des traitements est plus fréquent que le sous dosage. Le délai avant récolte (DAR) n'est pas pris en considération.

Un agriculteur a réalisé trois sarclages $(11,16$ et $18 \mathrm{SAP}$ ), trois ont réalisé deux sarclages alors que le cinquième a abandonné sa culture. Le premier sarclage est pratiqué entre la septième et la onzième semaine après la plantation de la courgette (SAP). D'après Lonsbary et al. (2003), les cucurbitacées sont peu compétitives avec les adventices au cours des premières SAP. La période critique d'interférence de la courgette avec les adventices s'étale sur les quatre premières SAP (Huffman, 2007). Les agriculteurs pratiquent les sarclages de façon aléatoire puisque la courgette était enherbée au cours de sa période critique d'interférence avec les adventices (Tableau 7). Le meilleur désherbage commence par un bon établissement de la culture et une maîtrise totale des adventices durant les premières SAP. Les sarclages tardifs indiquent un mauvais établissement de la courgette. De plus, un désherbage vers la fin du cycle de la culture permet d'empêcher l'enrichissement du stock semencier du sol. Le désherbage des inter-rangs

TABLEAU 5. Fertilisation de la culture de courgette de saison chez cinq agriculteurs du PPI de Chott Meriem (en \% de la dose référence)

\begin{tabular}{lcccccc}
\hline Engrais & $\mathrm{AB}$ & $\mathrm{FB}$ & $\mathrm{FL}$ & $\mathrm{ML}$ & SO & Référence $^{1}$ \\
\hline $\mathrm{N}$ & 49 & 11 & 21 & 68 & 15 & 220 \\
$\mathrm{P}_{2} \mathrm{O}_{5}$ & 49 & 3 & 94 & 126 & 2 & 110 \\
$\mathrm{~K}_{2} \mathrm{O}$ & 3 & 2 & 3 & 11 & 0 & 560 \\
\hline
\end{tabular}

1. Dose recommandée (Kg ha-1) (Ctifl, 2002)

TABLEAU 6. Traitements phytosanitaires de la culture de courgette de saison chez cinq agriculteurs du PPI de Chott Meriem

\begin{tabular}{lccllll}
\hline Agriculteur & Fongicides & Insecticides & $>\mathrm{DR}^{1}$ & $\mathrm{DR}^{1}$ & $<\mathrm{DR}^{1}$ & $\mathrm{RH}^{2}$ \\
\hline AB & 5 & 1 & $33.3 \%$ & 0 & $16.6 \%$ & $50 \%$ \\
FB & 2 & 2 & $25 \%$ & 0 & 0 & $25 \%$ \\
FL & 3 & 1 & $25 \%$ & $25 \%$ & 0 & $50 \%$ \\
ML & 4 & 2 & $16.6 \%$ & $33.3 \%$ & 0 & $50 \%$ \\
SO & 0 & 0 & 0 & 0 & 0 & 0 \\
\hline
\end{tabular}

'Dose recommandée

${ }^{2}$ Respect de l'homologation spécifique à la culture 
est fait par la traction animale. La gestion des adventices sur le rang est basée sur le désherbage à la sape qui est exigeant en journées de travail $\mathrm{ha}^{-1}$. Cette charge est un fardeau financier pour les agriculteurs (Melander et Rasmussen, 2001). A cela s'ajoute le problème de rareté et d'incompétence de cette main d'œuvre.

La récolte a débuté vers mi-mars à raison de deux récoltes par semaine. C'est au cours de cette période que le prix de vente est le plus élevé. En avril, les ouvrières doivent passer tous les jours pour éviter de se retrouver avec des courgettes de gros calibre $(>20 \mathrm{~cm})$ non commercialisables. Le rendement le plus élevé n'a pas dépassé les 33 tonnesha $^{-1}$ tandis que le plus bas est de 6 tonnesha ${ }^{-1}$ (Fig. 3). Ces rendements sont largement inférieurs à ceux des pays développés : En France, par exemple, ils sont de 55 à 80 tonnesha $^{-1}$ (Ctifl, 2002). La chambre d'agriculture Languedoc Roussillon a enregistré des rendements moyens de 65 tonnesha $^{-1}$ en 2012.Les rendements obtenus reflètent la conduite aléatoire de l'itinéraire technique et le manque d'encadrement des agriculteurs par les services de vulgarisation agricole.

\section{CONCLUSION}

Le diagnostic agronomique de la culture de courgette a permis d'analyser les pratiques culturales de la culture de courgette de saison chez cinq agriculteurs du PPI de Chott Meriem et d'y appréhender les contraintes de production. La variabilité des ITK d'un agriculteur à un autre reflète l'absence d'un référentiel spécifique à la culture de courgette. La conduite aléatoire de la culture influe négativement sur sa productivité. A part les difficultés techniques, les agriculteurs éprouvent une difficulté financière. Ils sont incapables de s'approvisionner à l'avance par manque de liquidité financière. Ceci les rend dépendants des points de vente des matériels agricoles et d'approvisionnement en semences et produits de fertilisation, limite leurs choix, et freine leur capacité de planification. L'amélioration de leur situation socio-économique exige un meilleur encadrement technique de ces agriculteurs. Les conseillers agricoles doivent inciter les agriculteurs à respecter les ITK des cultures dans le cadre d'un système de culture 


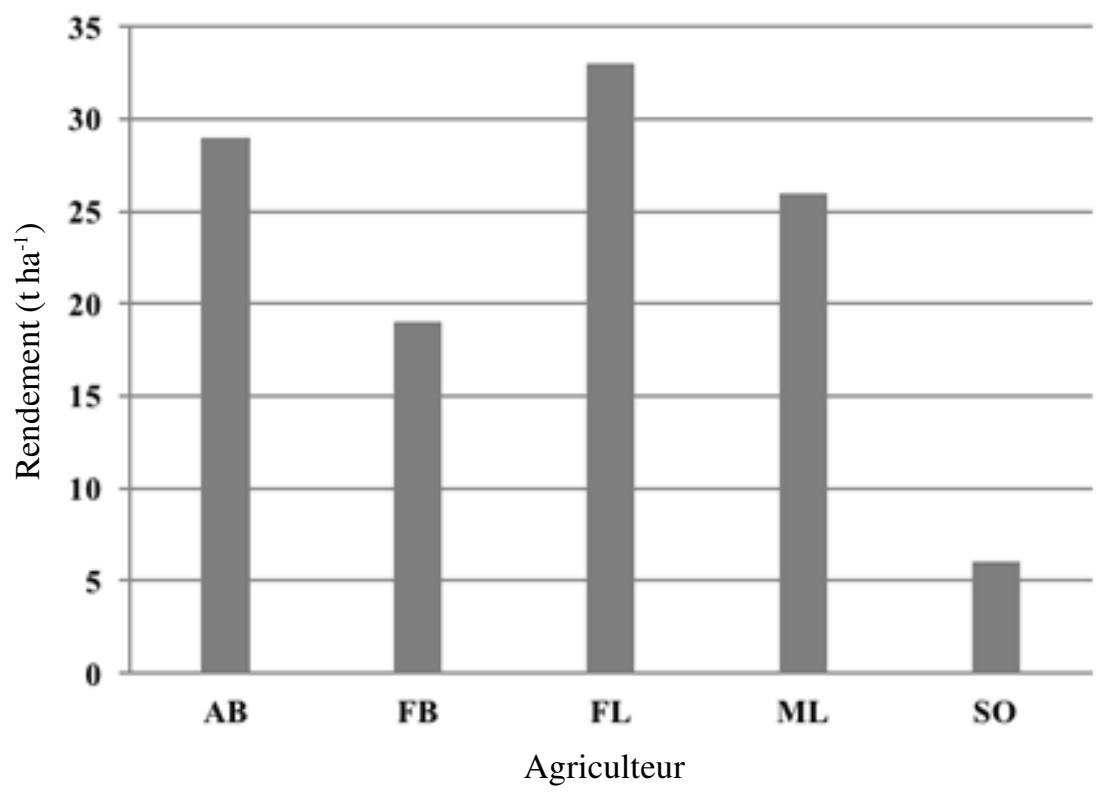

Figure 3. Rendement total de la culture de courgette chez cinq agriculteurs du PPI de Chott Meriem

planifié. L'agriculteur doit, considérer le système de culture comme une entité cohérente où tous les éléments sont interdépendants, plutôt qu'à chercher à optimiser chaque technique indépendamment des autres.

\section{BIBLIOGRAPHIE}

Abatzian, V., Lizot, J.F., Collin, F., Brun, L., Laurent, E., Broucqsault, L.M., Rey F. et Haefliger, M. 2003. Produire des semences de courgette dans un itinéraire agrobiologique. Fiche technique de l'institut technique agricole de l'agriculture biologique (ITAB). http:// www.itab.asso.fr/downloads/ Fichestechniques semences. Consulté Mars 2016.

Bouchy, J.F. 2011. La conduite de l'irrigation en maraîchage bio. Synthèse technique réalisée par l'association BLE - CIVAM Pays Basque. http://www.latelierpaysan.org/IMG/pdf/ 76819159.pdf. Consulté Mars 2016.

Byerlee, D. 1991. Monitoring farmers' practices and fields as a continuing activity in on farm research for evolving cropping systems. $J$. Asian Farm. Syst. Assoc. 1: 179-190.

Conseil, M., Cartaud, G. et Bourdais, R. 2009. La production biologique de courgettes en
Bretagne. Plateforme Agrobiologique d'Inter Bio Bretagne à Suscinio, Morlay.http:// www.doc-developpement-durable.org/file/ Culture-plantes alimentaire. Consulté Mars 2016.

Ctifl, 2002. La courgette. Centre technique interprofessionnels des fruits et des légumes, France. 30pp.

EPPO. 2004. European and Mediterranean Plant Protection Organization. Good plant protection practice. Cucurbits under protected cultivation. EPPO Bulletin 34: 9 - 100.

Espagnacq, L. 2015. La courgette en agriculture biologique. Fiche technique de la Chambre d'Agriculture Haute-Garonne. http:// www.haute-garonne.chambagri.fr/IMG/pdf/ Fiche courgette.pdf. Consulté Mars 2016.

FAO, 2010. Calendrier cultural, un outil d'information pour la sécurité semencière. http://www.fao.org/agriculture/seed/ cropcalendar/locale.do?pagename $=$ $\% 2$ Fwelcome.do\&language $=$ fr. Consulté Mars 2016.

Garcia, J. 2008. Courgette et concombre de plein champ. Fiche Technique Production Développée en Languedoc-Roussillon. http:/ /www.gard.chambagri.fr/fileadmin/Pub/ CA30/Internet CA30/Documents 
Internet CA30/Diversification Fiches/ Fiche Courgette Concombre.pdf. Consulté Mars 2016.

Guillou, M., Guyomard, H., Huyghe, C., Peyraud, J.L., Vert, J. et Claquin, P. 2013. Le projet agroécologique : Vers des agricultures doublement performantes pour concilier compétitivité et respect de l'environnement. Propositions pour le Ministre, INRA et AGREENIUM. $163 p p$.

Hillger, D.E., Weller, S.C., Maynard, E.T. and Gibson, K.D. 2006. Emergent weed communities associated with tomato production systems in Indiana. Weed Science 54: 1106-1112.

Houimli, E. 2008. Les facteurs de résistance et de fragilité de l'agriculture littorale face à l'urbanisation: Le cas de la région de Sousse Nord en Tunisie. Thèse de Doctorat. Université Agro Paris Tech., France. 418pp.

Huffman, L. 2007. Strategies for managing weeds: Stale seedbed, tillage, plasticulture. Great Lakes fruit, vegetable and farm market EXPO. Cucurbit IPM Workshop. DeVo Place Convention Center, Grand Rapids, MI. 16 pp.

ITCMI, 2010. Fiches techniques valorisées des cultures maraîchères et Industrielles : La culture de Courgette. Publication de l'Institut Technique des Cultures Maraîchères et Industrielles. République Algérienne Démocratique et Populaire Ministère de l'Agriculture et du Développement Rural. http://www.itcmidz.org/index htm files/ COURGE 1.pdf. Consulté Avril 2016.

JORT, 2002. Catalogue officiel des variétés végétales. Journal officiel de la république tunisienne. $41 \mathrm{pp}$.

Laajimi, A. 2007. Les périmètres irrigués en Tunisie. Un enjeu pour le développement de la production agricole. Les notes d'alerte $d u$ CIHEAM 30: 3 .

Lithourgidis, A.S., Dordas, C.A., Damalas C.A. and Vlachostergios, D.N. 2011. Annual intercrops: An alternative pathway for sustainable agriculture. Australian Journal of Crop Science 5(4): 396-410.

Lonsbary, S.K., O'Sullivan, J. and Swanton, C.J. 2003. Stale-seedbed as a weed management alternative for machine-harvested Cucumbers
(Cucumis sativus). Weed Technology 17: 724 $-730$.

Loyce, C. et Wery, J. 2006. Les outils des agronomes pour l'évaluation et la conception de systèmes de culture. In: Doré, T., Le Bail, M., Martin, P., Ney, B. et Roger-Estrade, J. (Eds.). L'agronomie aujourd'hui, Quae, Paris. 95pp.

McGrath, M.T. 2007. Challenges of powdery mildew, leaf blights and other diseases. Great Lakes fruit, vegetable and farm market EXPO. Cucurbit IPM Workshop, Grand Rapids, MI. 16 p.

Melander, B. and Rasmussen, G. 2001. Effects of cultural methods and physical weed control on intrarow weed numbers, manual weeding and marketable yield in direct-sown leek and bulb onion. Weed Research 41: 491-508.

Meynard, J.M. 2012. La reconception est en marche Conclusion au Colloque « Vers des systèmes de culture innovants et performants: De la théorie à la pratique pour concevoir, piloter, évaluer, conseiller et former. Innovations Agronomiques 20:143-153.

Moephuli, S. 2013. Production guideline for summer vegetables. Agricultural Research. Council Vegetable and Ornemental Plant Institute (ARC-VOPI). 44pp. http:// www.arc.agric.zal

Mohamed, M. 2009. Le climat agricole au Sahel tunisien et les changements climatiques. Mémoire. Université du Québec à Montréal, Canada. 162pp.

Montagnon, A.S. 2004. La gestion de l'interculture. Ed. Educagri éditions. 176pp.

Salata, A. and Stepaniuk, R. 2012. The effect of drip irrigation on zucchini cultivar 'Soraya' yielding. Annales univetsitatis Mariae CurieSklodowska Lublin_Polonia 22 (3): 22-28.

Schonbeck, M. 2015. Weed management strategies for organic cucurbit crops in the southern United States. eOrganic's 4573. http://articles.extension.org/pages/60198/ weed-management-strategies-for-organiccucurbit-crops-in-the-southern-unitedstates\#.VkeO1nYvfIU. Consulté Mars 2016.

Sébillotte, M. 1978. Itinéraires techniques et évolution de la pensée agronomique. C.R. Acad. Agric. Fr. 64 (11): 906-914. 
Sébillotte, M. 1990. Système de culture, un concept opératoire pour les agronomes. In: Combes, L. et Picard, D. Les systèmes de culture, INRA, Paris. pp. 165-196.

Skiredj, A., Elattir, H. et Elfadl, A. 2012. La culture de gombo. Publication de l'Institut Agronomique et vétérinaire Hassan II, Département d'horticulture. http:// www.legume-fruit-maroc.com/gombo.php. Consulté Mars 2016.
TAP. 2015. Nécessité de mieux gérer les périmètres irrigués en Tunisie. Tunisie Afrique Presse. http://www.tap.info.tn/fr/index.php/ economie/agriculture-environnement/45215les-perimetres-irrigues-doivent-etre-mieuxgeres-en-tunisie. Consulté Mars 2016.

Tilman, D. 1999. Global environmental impacts of agricultural expansion: The need for sustainable and efficient practices. Proc. Natl. Acad. Sci. 96: 5995-6000. 